\title{
Microvascular reconstruction of a full thickness scalp and skull defect following herpes zoster infection
}

\author{
Ariel A Waitzman MD, Peter C Neligan MB BCH FRCS(I) FRCSC \\ Department of Otolaryngology, and the Division of Plastic Surgery, Department of \\ Surgery, The Toronto Hospital, and The University of Toronto, Toronto, Ontario
}

\begin{abstract}
AA Waitzman, PC Neligan. Microvascular reconstruction of a full thickness scalp and skull defect following herpes zoster infection. Can J Plast Surg 1996;4(4):213216. Herpes zoster is a common infection caused by reactivation of the varicella zoster virus. In most patients the disease runs a painful but benign course with complete recovery. A unique case of trigeminal ophthalmic herpes zoster presented to The Toronto Hospital, Toronto, Ontario. This patient had a unilateral full thickness defect of scalp and skull with secondary osteomyelitis and opacification of the eye. After appropriate medical therapy and surgical debridement, reconstruction was undertaken using a latissimus dorsi free flap and split thickness skin grafts. This achieved a satisfactory reconstruction with obliteration of the diseased tissue. On follow-up several months later, there was erosion through the central area of the skin graft. This appears to be secondary to trauma caused by the patient frequently scratching the area, and that the original defect likely had a factitious component of the same etiology.
\end{abstract}

Key Words: Free flap, Herpes zoster, Microvascular, Scalp, Shingles

Reconstruction microvasculaire d'une lésion pleine épaisseur du cuir chevelu et du crâne après une infection à herpès zoster

RÉSUMÉ : L'infection à herpès zoster est souvent causée par une réactivation du virus de la varicelle. Chez la plupart des patients, la maladie évolue sans danger, mais douloureusement, et la récupération est complète. Un cas unique d'herpès zoster ophtalmique trigéminé a été observé à l'Hôpital de Toronto, à Toronto en Ontario. Le patient présentait une lésion unilatérale de pleine épaisseur du cuir chevelu et du crâne avec ostéomyélite secondaire et opacification de l'oeil. Après un traitement médicamenteux approprié et un débridement chirurgical, la construction a été entreprise à l'aide d'un lambeau libre prélevé à partir du grand dorsal et de greffons de peau d'épaisseur partielle. Les résultats ont été satisfaisants avec oblitération des tissus lésés. Au moment du suivi, quelques mois plus tard, on a noté une érosion à la région centrale du greffon cutané qui a semblé être secondaire à un traumatisme causé par le fait que le patient se grattait souvent la tête et la lésion d'origine s'accompagnait probablement d'une composante factice de même étiologie. 
Herpes zoster or shingles is a common condition with a prevalence of approximately four per 1000 persons (1). It is caused by the large DNA-enveloped varicella zoster virus which initially infects many children and young adults and presents as chicken pox. After the initial infection the virus tends to lie dormant in the ganglia of sensory nerves (2). When the virus is reactivated it manifests as shingles, a painful vesicular eruption affecting the skin and mucous membrane supplied by the involved nerve. There is often prodromal pain in the involved dermatome two to 14 days before vesicle formation. The vesicles then tend to rupture and coalesce, leading to crusting (1). The lesions typically heal in seven to 14 days, usually with no scar formation $(2,3)$. The trigeminal nerve is involved in $18.5 \%$ of cases (1). The ophthalmic branch of the trigeminal nerve $\left(\mathrm{V}_{1}\right)$ is involved 10 times more often than the maxillary or mandibular branches, and the eye itself is involved in one half of these cases (1). A case of $V_{1}$ herpes zoster with secondary bacterial osteomyelitis presented to The Toronto Hospital, Toronto, Ontario, providing an interesting reconstructive challenge.

\section{CASE PRESENTATION}

A 50-year-old retired male presented to his family physician in July 1993. He had a painful vesicular rash on his left forehead and left tip of nose. He was diagnosed as having $\mathrm{V}_{1}$ (trigeminal ophthalmic) herpes zoster with sparing of the eye. He was admitted to hospital in northern Ontario and given a 10-day course of intravenous acyclovir. After discharge he was lost to follow-up. In December 1993, he presented again with a similar left facial rash and eye involvement. An ophthalmologist was consulted, and the patient received a course of intravenous acyclovir and antibiotics, as well as gentamycin eye drops. His compliance was poor, and it was likely that he did not receive a full course of therapy. The patient was again lost to follow-up, but returned in April 1994 to the ophthalmologist for assessment. He complained of blindness in his left eye and pain from a large wound on his left forehead region. He was then transferred to The Toronto Hospital for management.

When examined by the authors the patient had a large wound involving the left frontoparietal region and left upper eye lid (Figure 1). The wound was relatively clean and granulating. An opening into the left frontal sinus was visible through the wound. There was a small amount of purulent exudate in the wound but no frankly necrotic material. The left eye was completely opacified and had no vision or light perception. There was some mild scarring on the left distal half of the nose and a small cleft of the left alar rim. Culture swabs were taken from the wound and eye. A biopsy, including tissue from the wound edge and calvarium from the eroded bone edge, was performed. The patient's history was otherwise unremarkable except for noninsulin-dependant diabetes mellitus which was controlled with oral glyburide. 

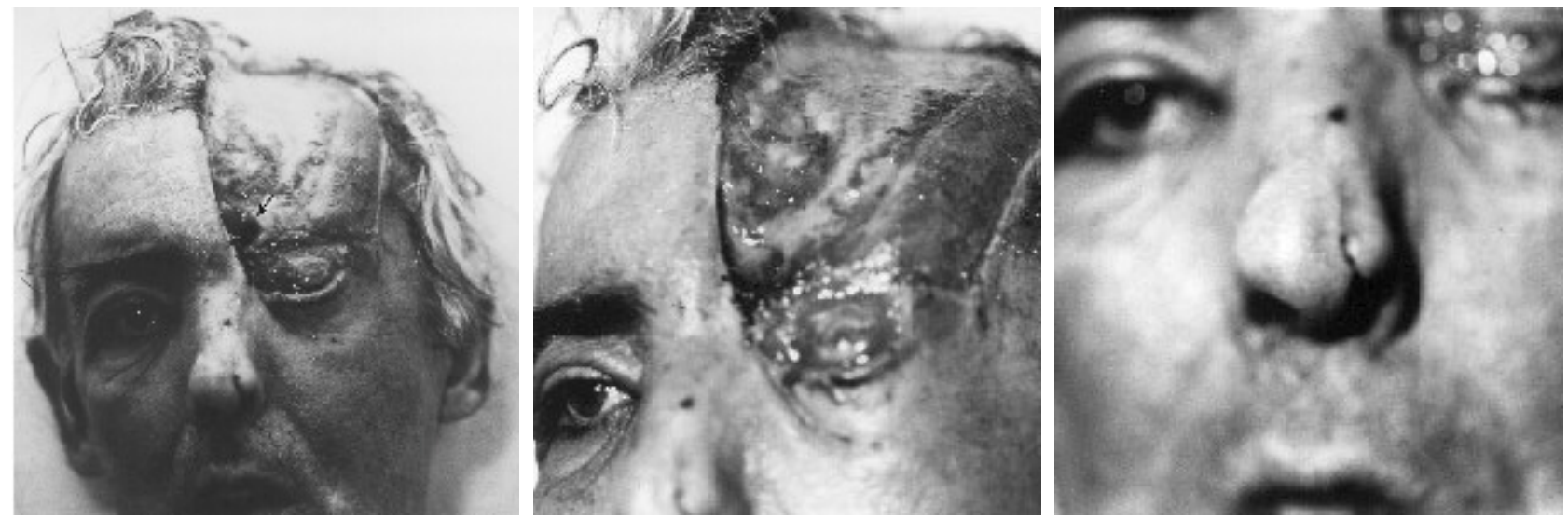

Figure 1) Photographs of patient demonstrating left forehead defect, left eye opacification, left nasal alar clefting, and opening into left frontal sinus (Arrow, far left)

Several other services were consulted including endocrinology, ophthalmology, infectious disease, neurosurgery and neuroradiology. The left eye was deemed unsalvageable, and the patient was started on tobramycin eye drops until definitive management was undertaken. Initial culture results from the eye, wound swabs and bone specimen were positive for Staphylococcus aureus. Intravenous cloxacillin was then started. A computed tomography (CT) scan of the head and face using axial and coronal cuts was completed (Figure 2). This revealed a large soft tissue defect involving the frontal bone on the left side from the midline over. There was a defect in the anterior wall of the left frontal sinus, with surrounding sclerosis consistent with osteomyelitis. There was no identifiable bony cortex over the left superior cranium with direct exposure of dura. No underlying brain pathology was seen.
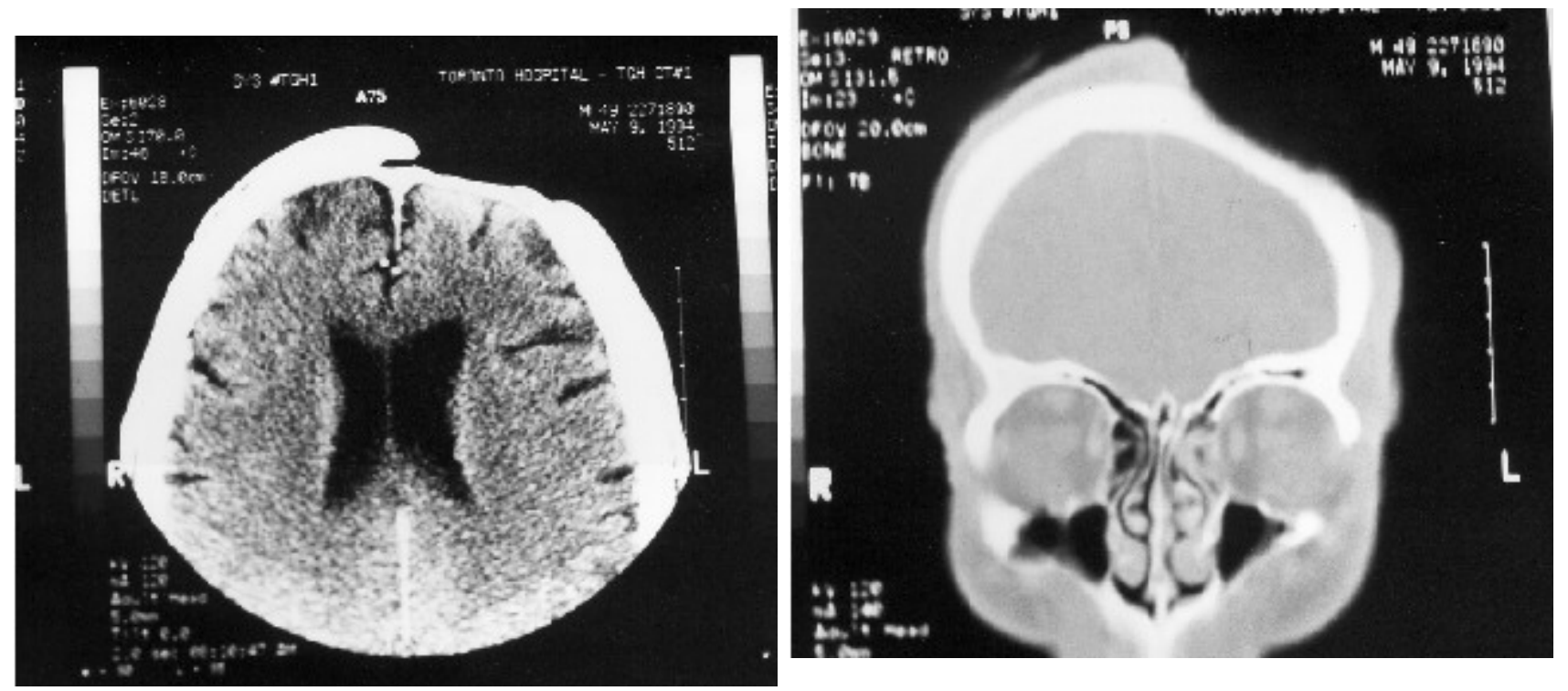

Figure 2) Left Axial and Right coronal computed tomography scans demonstrating full thickness bone defect in left frontal region 


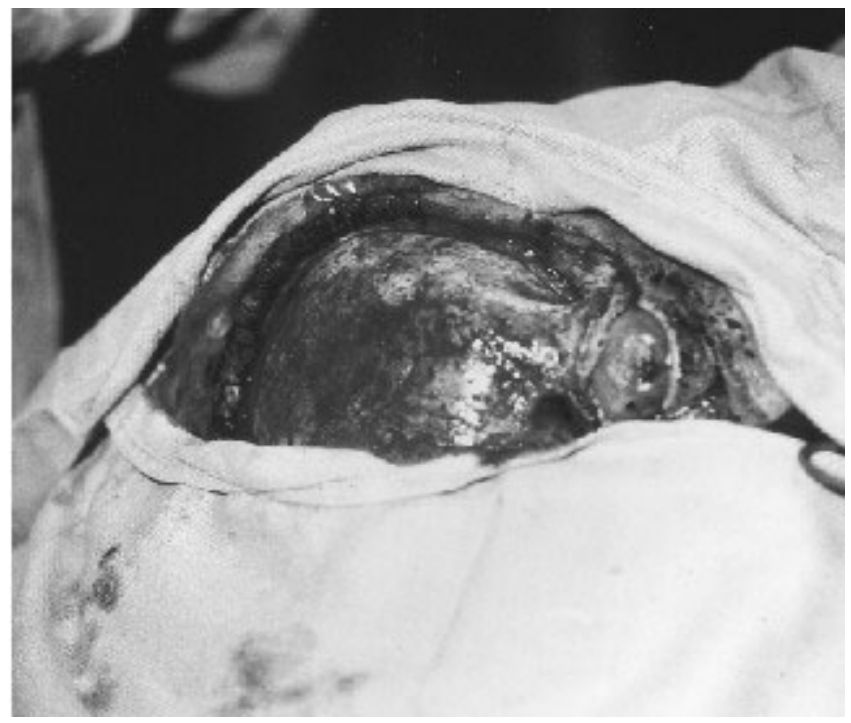

Figure 3) Intraoperative photograph after wound debridement and eye evisceration; patient is in right side down position

After receiving a six-week course of intravenous cloxacillin the patient was taken to the operating room. The wound was thoroughly debrided, removing all necrotic tissue and left frontal sinus mucosa, and the left eye was eviscerated with sparing of the intraorbital muscle cone (Figure 3).

A left latissimus dorsi free flap was harvested and secured into the wound cavity. The vessels of the flap pedicle were anastomosed to the left superficial temporal artery and vein. The muscle was covered with a nonmeshed split thickness skin graft harvested from the left thigh (Figure 4).

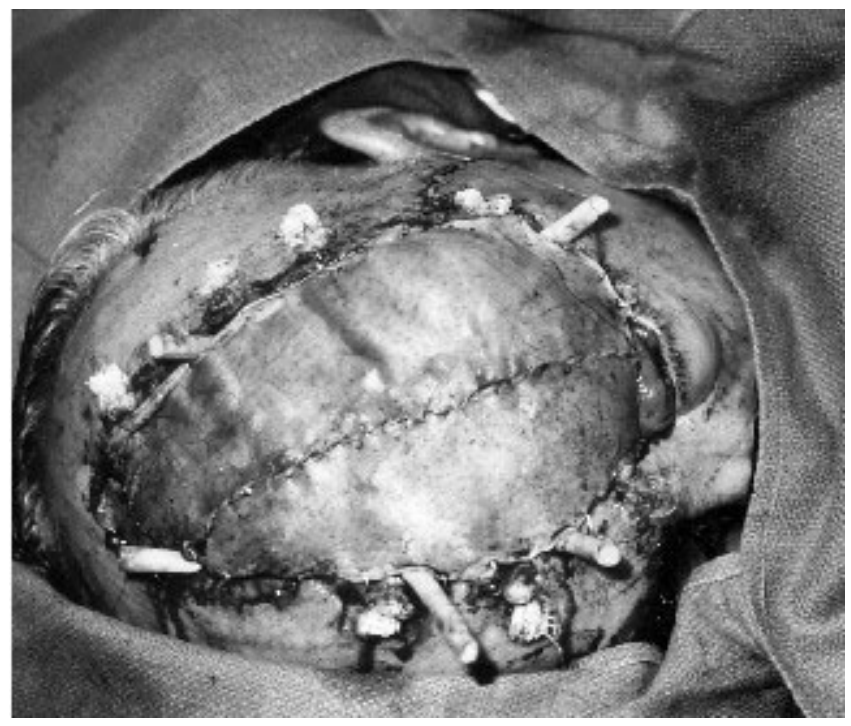

Figure 4) Intraoperative photograph with latissimus dorsi free flap and split thickness skin grafts in place, and Penrose drains around flap perimeter 
Intravenous cloxacillin was continued for two weeks after surgery. The pathology report from the debrided tissue showed only granulation tissue and normal bone. At two months postreconstruction, the flap was completely viable with excellent skin graft take (Figure $5)$.
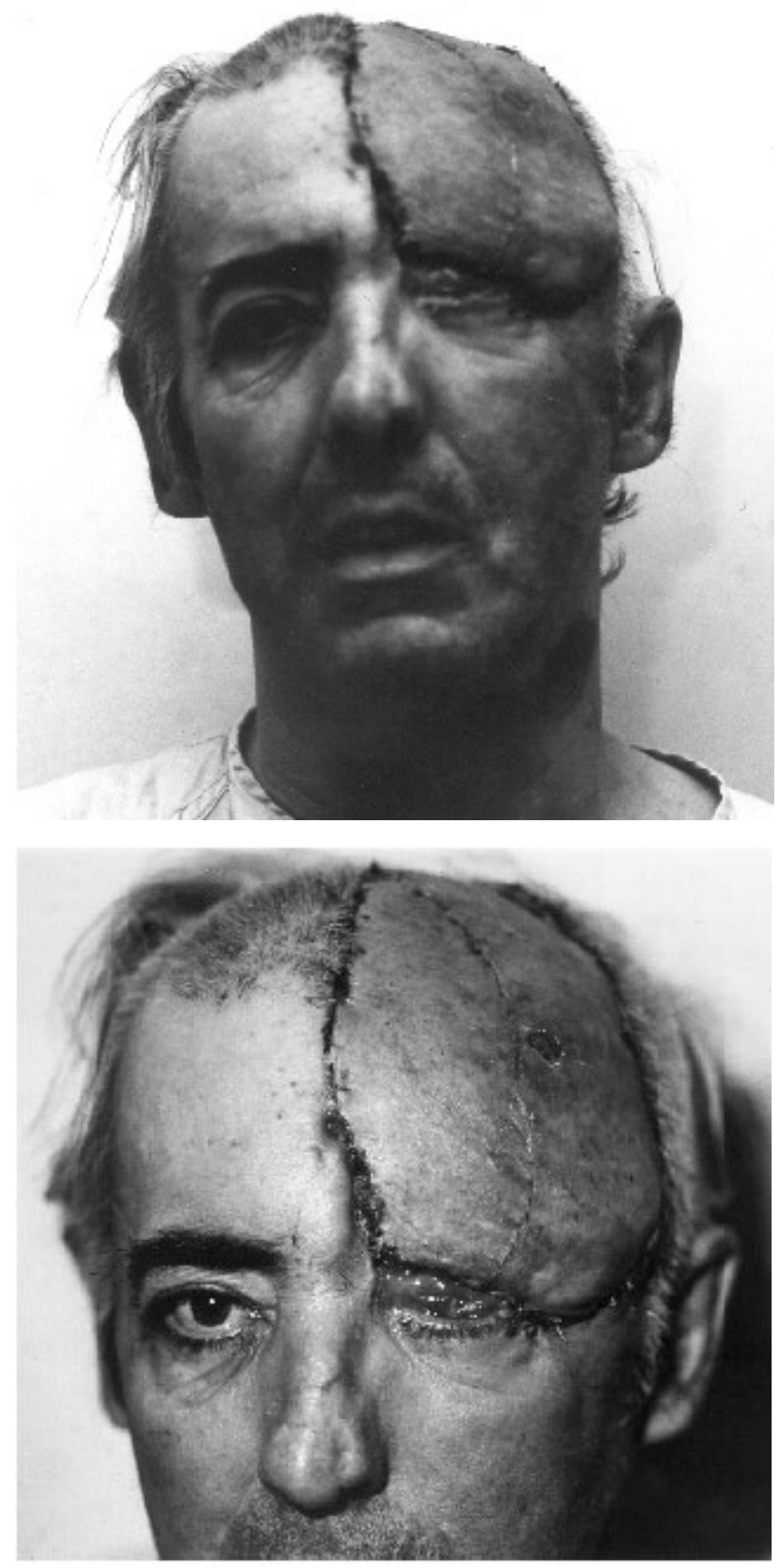

Figure 5) Photographs of patient eight weeks following surgery 


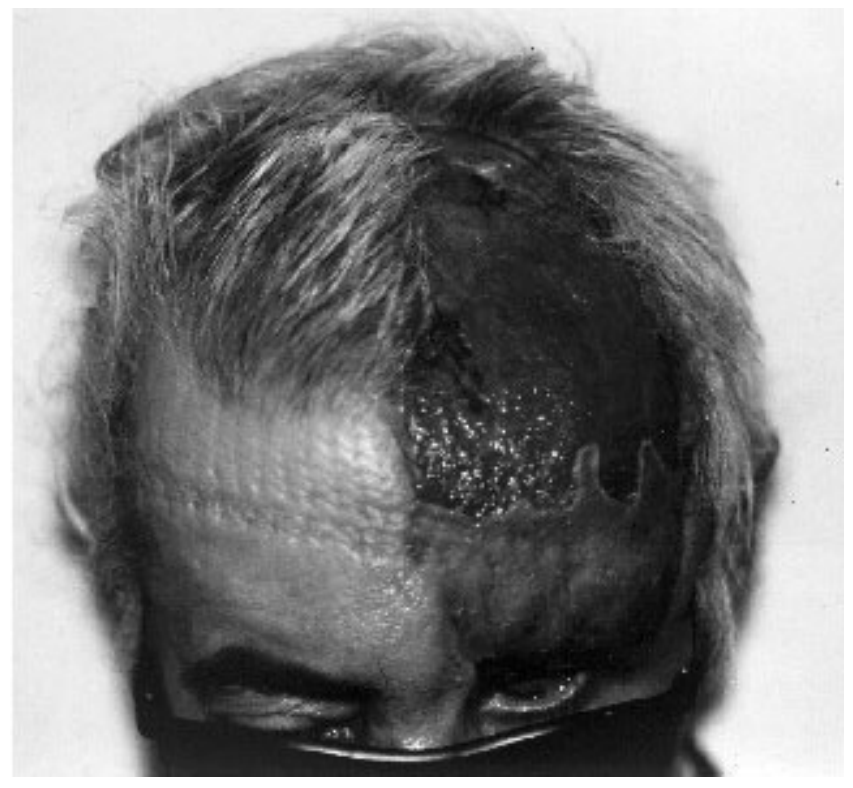

Figure 6) Photograph of patient 14 months following surgery showing partial loss of the skin graft

Unfortunately, the patient felt that the flap was too bulky and proceeded to scrape off the skin graft with his fingernails. On follow-up in August 1994 there was partial loss of the skin graft, but the underlying flap was viable (Figure 6). The flap was debrided and regrafted. The skin graft has remained stable at six months follow-up, and the patient will be fitted with a prosthetic eye in the future.

\section{DISCUSSION}

Reactivation of the varicella zoster virus may occur in healthy adults, with the chances increasing with age, and it is often seen in individuals with compromised immune systems. Herpes zoster is commonly seen in patients with acquired immunodeficiency syndrome or malignancy, and in organ transplant recipients on immunosuppressive medications (4). Diabetes mellitus also causes impairment of immune function and likely played a role in this case. The most common complication of herpes zoster infection is postherpetic neuralgia which occurs in $9 \%$ of cases (4). Other complications include anesthetic white skin scars, myelitis, meningoencephalitis, musculoparalysis, vestibulocochlear damage, cranial and extracranial nerve palsies, damage to the sclera, ciliary body and cornea of the eye, and disseminated zoster $(1,5)$. Bony involvement from herpes zoster infection is very rare. There are only 24 cases reported of bone necrosis following trigeminal herpes zoster $(1,2,6)$. These were split evenly between the maxilla and mandible, and were associated with tooth exfoliation. There are no reported cases involving the frontal bone or calvarium. Patients ranged in age from 12 to 85 years, and one-half of these patients had a major illness preceding the onset of the herpes zoster infection. In these cases the bone necrosis occurred three to 12 weeks after the onset of herpes zoster infection $(2,6)$. The pathophysiology of bone 
necrosis is unknown, but several theories exist. A leukocytoclastic vasculitis mainly involving the postcapillary venules has been reported in association with herpes zoster infection. This may represent a direct extension of the neural inflammatory process and may eventually cause infarction and necrosis of the involved bone $(2,7)$. Viral infection of the trigeminal nerve branches and/or sympathetic fibres supplying the periosteum and periodontium may lead to avascular necrosis of the involved bone (2). Necrotic bone produced by either of these processes may become secondarily infected, resulting in osteomyelitis. A third explanation, which the authors believe played a role in the above case, is a secondary bacterial or fungal infection of the skin and soft tissues affected by the herpes zoster. If neglected or inadequately treated this infection may progress to involve the underlying bone.

This case presented a challenge with respect to controlling the local disease process and the definitive reconstruction. After appropriate investigations and receiving microbiological culture results the patient received a full course of intravenous antibiotic. After debridement a large defect remained with exposed dura. A latissimus dorsi free flap was chosen for its large surface area and appropriate bulk following atrophy of the flap. This provided adequate coverage of the wound with well vascularized tissue and protection of the dura and underlying brain. A nonmeshed split thickness skin graft was used to improve the appearance of the flap. At follow-up two months after surgery it was apparent that the patient had eroded the skin graft by scratching it. The authors believe that it is highly likely that this factitious etiology played a major role in creating the original defect.

\section{REFERENCES}

1. Schwartz O, Kvorning SA. Tooth exfoliation, osteonecrosis of the jaw and neuralgia following herpes zoster of the trigeminal nerve. Int J Oral Maxillofac Surg 1982;11:36471.

2. Mintz SM, Anavi Y. Maxillary osteomyelitis and spontaneous tooth exfoliation after herpes zoster. Oral Surg Oral Med Oral Pathol 1992;73:664-6.

3. Mostofi R, Marchmont-Robinson H, Freije S. Spontaneous tooth exfoliation and osteonecrosis following a herpes zoster infection of the fifth cranial nerve. J Oral Maxillofac Surg 1987;45:264-6.

4. Weller TH. Varicella and herpes zoster: A perspective and overview. J Infect Dis 1992;166(Supp1):1-6.

5. Peterslund NA. Management of varicella zoster infections in immunocompetent hosts. Am J Med 1988;85(Supp2A):74-7.

6. Muto T, Tsuchiya H, Sato K, Kanazawa M. Tooth exfoliation and necrosis of the mandible - A rare complication of trigeminal herpes zoster. J Oral Maxillofac Surg 1990;48:1000-1003.

7. Cohen C, Trapuckd S. Leukocytoclastic vasculitis associated with cutaneous infection by herpes virus. Am J Dermatopathol 1984;6:561-4. 